DOI: https://doi.org/10.11144/Javeriana.umed61-4.nvoz

\title{
La niña sin voz y su madre invisible
}

Recibido: 20 Marzo 2020 | Aceptado: 22 Mayo 2020

\author{
Catalina Vargas-Acevedo \\ Médica residente de Pediatría, Universidad de los \\ Andes-Hospital Universitario Fundación Santa Fe de \\ Bogotá, Colombia
}

a Autora de correspondencia: cv.acevedo@uniandes.edu.co

Cómo citar: Vargas-Acevedo C. La niña sin voz y su madre invisible. Univ. Med. 2020;61(4). https://doi.o $\mathrm{rg} / 10.11144 / J a v e r i a n a . u m e d 61-4 . n v o z$
Una sonrisa habla en la niña sin voz. Una mirada habla en la niña sin voz. Pero en su madre invisible, en su madre sin lenguaje, su mirada invisible, su sonrisa invisible, callan en un silencio eterno, un silencio sin lectura ni posibilidad de interpretación.

Hace poco, dentro de mi práctica clínica, me encontré con una niña pequeña de una comunidad indígena y con su madre, quien no hablaba español. La lectura de mis pacientes y de sus padres siempre se me ha facilitado como un libro abierto expuesto para su interpretación. Una lectura juiciosa y detallada me llena de herramientas para transmitir un mensaje, para comunicar, para explicar y poder tomar decisiones y conductas. El sillón de terciopelo verde que nos pide Cortázar es, usualmente, el lugar de mayor comodidad para mí al enfrentarme a mis pacientes y sus padres, el proceso de una empatía sincera, sencilla y delicada que me permite dibujar, casi siempre, una sonrisa de acuerdo y aprobación. Pero en la niña sin voz y su madre invisible, la pérdida del lenguaje, de toda índole, me dejó sin herramientas y le quitó definitivamente la importancia a mi voz.

La madre invisible nació invisible. Una niña invisible en una de las amplias selvas tropicales de este país. Hecha invisible por su cultura, que también es nuestra, por su padre, por sus hermanos, por sus hombres y por sus mujeres, hecha invisible, sin voz. Dentro de la historia de la niña sin voz me voy a abstener, en la medida de lo posible, de dar un juicio de valor, un juicio desde el beneficio, desde la sensación — falsa - de superioridad que descansa sobre nuestra ignorancia de otras culturas; pero en términos médicos me cuesta mucho no juzgar.

La niña sin voz nació con un corazón roto, pero con uno de aquellos agujeros susceptibles de ser corregidos. Nació en un contexto difícil, en un lugar recóndito y en condiciones incomprensibles. La niña sin voz nació sin 
controles prenatales y como sexta hija de su madre invisible. Con una hipoxia neonatal y pobre seguimiento médico, la niña sin voz fue creciendo sin $\mathrm{vOz}$, con su corazón apostando por cada latido. Por las valiosísimas brigadas de instituciones del corazón y con gran corazón, se logró identificar la enfermedad cardiaca de la niña sin voz y se recomendó una corrección temprana; pero sus padres no lo permitieron. Al final, se logró intervenir, tardía pero efectivamente. Sin embargo, el resultado de una hipoxia perinatal y una bomba con paro circulatorio le habían dejado un retraso en su neurodesarrollo que le impedía tragar y la ponía en alto riesgo de broncoaspirar hasta que, poco antes de conocerla, la niña sin voz broncoaspiró y requirió maniobras de reanimación avanzada para volver a respirar. Con aún más daño a su cerebro inmaduro, la niña sin voz empezó a comer por una sonda y con su madre invisible, las dos invisibles, pasaron semanas en un albergue en la ciudad fría y en un idioma ajeno que las ocultaba aún más.

Yo conocí a la niña sin voz ante la emoción de encontrarme con un corazón malformado y de entender su flujo y sus presiones. $\mathrm{Al}$ poco tiempo de conocerla, entendí que en este caso no debía escuchar su corazón, sino su sonrisa. La sonrisa en la niña sin voz me hablaba a gritos y me pedía ser escuchada. La sonrisa en la niña sin voz contaba su testimonio, contaba su vida más allá de su lesión cerebral. Ella me miraba y sonreía, la examinaba y sonreía, la puncionaban y sonreía, le pasaban una sonda nasogástrica y sonreía; mientras su madre invisible pataleaba en un mar sin palabras, ahogada en la incomprensión.

La sonrisa de la niña sin voz y el dolor de su madre invisible testificaban la certeza de una historia escondida. Poco a poco, entre gestos y señales, y luego de pacientes e interminables esfuerzos de comunicación, entendí que la mayor sombra de la madre invisible era su culpa (pues su cultura la culpaba a ella por la enfermedad de su hija). Era entonces, su culpa por ser mujer, su culpa por ser invisible, a pesar de ser ellos, de ser él, los que la volvían invisible. Su culpa de haber parido, su culpa de engendrar iguanas (como tanto lo temía Úrsula Iguarán en Cien años de soledad), así hubieran sido ellos, él, los que la obligaban a parir y servir solo, ante él, para ser madre: madre invisible.

Otra sombra de la madre invisible era su cultura. Y aunque duele y cuesta entender que debamos llamarla sombra, en este caso, y en muchos otros, es una sombra difícil de penetrar. El lenguaje, y la dificultad para entendernos, no fue, paradójicamente, la mayor barrera, sino la dificultad de conexión empática entre ambas. En todos los intentos de comunicación, sentí que la madre invisible me lograba entender. Ante mis esfuerzos, lograba transmitir el mensaje, pero no encontraba una reacción emocional de su parte. Era como si se hubiese construido un muro, gigantesco y fundamental, a través de siglos y siglos de represión. Como si la represión histórica me estuviera cobrando cuentas a mí para no ser oída y para que mi mensaje fuese tomado como ajeno, como malintencionado y como intrusivo. Un muro que nos separaba definitivamente y dejábamos de ser colombianas, dejábamos de ser latinoamericanas y nos volvíamos ajenas; entre la madre invisible y ahora una médica invisible.

La decisión médica, en conjunto y con la rigurosidad requerida, fue la recomendación de una gastrostomía para asegurar la alimentación de la niña sin voz. La reacción de su madre invisible fue la de negarse sin voz, sin opinión, sin argumentos, pero con un no universal, con un no rotundo y certero. Un no a pesar de saber, o al menos eso creíamos, que sin eso no podría alimentarse, y que el riesgo de muerte sería inminente.

El argumento de la defensa del derecho superior del niño lo hemos tenido muchas veces y ha trascendido en diferentes escenarios. La primera reacción de cualquiera de nosotros es de creer que debemos justificarnos y hacer que la madre invisible acceda, pues indiscutiblemente tenemos la razón, indiscutiblemente todo lo que hacemos es para el mayor beneficio de la niña sin voz, que ante su mutismo necesita que hablemos por ella y la defendamos, a toda costa y con todos los recursos de los que disponemos.

Indiscutiblemente, definitivamente, o iserá que no? ¿Estamos seguros de que ese es el mayor beneficio para la niña sin voz? ¿Estoy segura, yo, 
de conocer las razones, de no estar juzgando a una madre invisible, hecha invisible por su cultura, que también es mía? ¿Será que prolongar su vida es la mejor forma en la que puedo, en la que podemos, darle voz? Pero, iclaro que sí! Si la mejor forma de darle voz es darle vida, si tengo que luchar por esa vida, si una predicción de una posible incapacidad o retraso cognitivo no es suficiente para dejar la discusión y otorgarle el mutismo final, o ¿sí lo es? No lo sé, no tengo idea y mi voz se empieza a perder, mi voz ante la niña sin voz pierde credibilidad y ante la madre invisible pierdo presencia.

Entiendo el contexto, entiendo las razones o, al menos, intento hacerlo. Creo comprender el valor de respetar la cultura indígena y otorgarle importancia —en lugar de juzgar- a sus creencias. Pero, ¿dónde está el límite? ¿Dónde están las guías de práctica clínica y la certeza de lo correcto e incorrecto para ayudarme a tomar una decisión o, al menos, darle tranquilidad moral a una conciencia que en este punto está agotada de la indecisión?

El silencio en la niña sin voz era inherente a su mutismo esencial; pero en su madre, a pesar de ser aquella barrera la que me evitaba una conexión empática con ella, daba la sensación de ser un silencio protector. Era invisible, y hecha invisible, dentro de lo ajeno de nuestra realidad, pero tal vez esa invisibilidad era una herramienta más de resguardo. ¿Qué protegía la madre invisible? Quizás, para ella se trataba de un lenguaje más claro, más puro y universal. Y era el mismo que yo percibí: la sonrisa de su hija. Una sonrisa que era su voz, su grito de defensa y certeza de una lucha cautelosa, silenciosa y fugaz. Y iqué más humano, qué más real y comprensible que la sonrisa de un niño? ¿Qué mayor muestra de vitalidad, de presencia y de voz ardiente que la sonrisa de su hija?

La intención de la historia de la niña sin voz, como ya dije, no es impartir juicio ni tampoco es compartir mi opinión, sino, más bien, compartir y hacer evidente la dialéctica moral y emocional a la que me veo sometida en estos casos. Crecemos, como médicos, dentro de una cultura de lo certero, lo medible y lo metódico. Pero, a la vez, tratamos con seres humanos diversos, con emociones que muchas veces cuesta describir. Entonces, a pesar de que debamos describir y estudiar rigurosamente su patología, no significa que la misma metodología se pueda implementar para analizar y sistematizar su alma, sus sentimientos, sus creencias y sus procesos cognitivos, intelectuales y emocionales. El alma, siendo irrelevante la comprensión explícita de este término (religiosa o no, política o no, real o no), es un componente de esa humanidad, de esa hermosa y fascinante humanidad, que aporta más de lo que reconocemos a nuestra práctica médica. Este es, entonces, un llamado a respetar la dialéctica, la indecisión, y a reconocer lo difícil que pueden ser las decisiones humanas. Después, por supuesto, se justifica sistematizar y crear procesos que nos ayuden a tomar las decisiones, entre todos, para que sean las más correctas posibles.

El humanismo y la humanidad, siendo su esencia diferente pero igual de importantes, han cobrado un gran peso en la formación médica actual. Ahora bien, siempre se ha hecho hincapié en recordar la humanidad del paciente. Recordar e intentar comprender las razones para sus conductas, llenarnos de habilidades de comunicación y de comprensión empática y evitar segmentarlo en órganos y sistemas. No obstante, y sin olvidar la importancia que eso tiene, idónde queda la humanidad del médico? Debemos entonces recordar nuestra propia humanidad. Nuestra esencia humana y el dolor, la rabia, la alegría y la inclemente veracidad que implica para el médico tomar decisiones humanas; por ello, creo, es un componente que se debe tener en cuenta en la discusión.

En el caso de la niña sin voz y su madre invisible, esto es lo que yo siento: siento la certeza de que el dilema, para mí, no tiene respuesta, que los argumentos pueden justificar ambas posturas y, posiblemente, ambas son válidas. Siento la intranquilidad del juicio de valor sobre una cultura que hace parte de nuestra identidad latinoamericana; me cuesta deglutir y genera una sensación de inconformidad. Pero también siento, profundamente y de manera desgarradora, la sensación de injusticia y de culpabilización de la mujer indígena y de esta madre invisible 
que no podía darle voz a su hija en lo ajeno de la cotidianidad. Siento la certeza del valor de la vida. Siento el desconocimiento de que mi juicio, o el de nuestra sociedad, de un futuro con menor o mayor capacidad cognitiva puede ser invalidado sencillamente por una sonrisa, por un grito de alegría, tenga o no utilidad finita. Siento, siento, siento, pero no tengo respuesta.

¿Será entonces que la respuesta yace en lo profundo de nuestra propia humanidad? Es más, no es una respuesta certera, sino más bien su proceso de búsqueda lo que quizás puede tener mayor valor que aquel concreto e indiscutible "sí o no". ¿Puede ser esta la solución que buscaba?

Al tratar con personas y reconocer qué significa esto, no siempre obtendremos respuestas concretas y tangibles, por lo que este es finalmente un llamado a que creamos, conozcamos y comprendamos nuestra fascinante, diversa, irremediable y hermosa humanidad como médicos y médicas, pues, al fin de cuentas, la medicina es el ser humano y la humanidad está en una sonrisa. 